\title{
Effects of Integrated Functional Adult Literacy Program Implementation in the Shashemene City
}

\author{
Birhanu Jima \\ Department of Adult Education and Community Development, college of Education and Behavioral Studies. \\ Madda Walabu University Bale Robe Ethiopia \\ Ayele Kumsa \\ Department of Adult Education and Community Development, college of Education and Behavioral Studies. \\ Madda Walabu University Bale Robe Ethiopia \\ Belachew Desalegn \\ Madda Walabu University Department of Agriculture
}

\begin{abstract}
The Purpose of this study was to assess Effects of Integrated Functional Adult Literacy program implementation in the Shashemene city Administration. Mixed methods of research design were employed. Data were gathered through questionnaire, interviews, focus group discussion and checklist. Out of 21 IFAE centers in sub-city, $10(47.6 \%)$ of them were included by using simple random sampling technique. Besides, out of 400 (390 adults learners and 10 facilitators), 120 was selected by Stratified and availability sampling techniques respectively. In addition, twenty four (24), 2 IFAE experts from education office, 4 City education supervisors, 2 Health extension workers, 5 school principals, 2 IFAE experts from women affairs, 5 Sub City chair person, 2 SME experts and 2 IFAE expert from youth and sport were purposively interviewed. Quantitative data were analyzed using descriptive statistics (percentage, frequency and mean). Qualitative data were analyzed using narrative and thematic description. The major findings revealed that the learners living condition of health care improved, parents were encouraged and send their children to school. However, poor integration and coordination among the sectors, lack of financial package, trained personnel and lack of interest and motivation of facilitators, low commitments among political leaders to sustain the program, were the major bottlenecks in the effects of IFAE program implementation. Therefore, to alleviate these problems, both Shashemene Administration city and Oromia Education Bureaus in collaboration should allocate necessary budget. Stakeholders participation should be encouraged; issues of: capacity building, facilitators payments, equipping IFAE centers with the necessary educational materials and facilities...etc should be clearly discussed with communities.
\end{abstract}

Keywords: Assessment Effects, Integrated, Functional, Adult Literacy, implementation

DOI: $10.7176 / \mathrm{JEP} / 11-13-02$

Publication date:May $31^{\text {st }} 2020$

\section{Background}

Education played big role as a major driver of economic competitiveness in an increasingly knowledge-driven global economy. Contemporary society has high expectations of the contribution that education can make in helping people learn to live with change, to lead change, and to support improvement in all spheres of life (Kala and Chaubey, 2015). Education is a prerequisite for short and long-term economic growth. As a result, no country has achieved continuous and rapid economic growth without at least 40 percent of adults being able to read and write (Merriam and Cunningham, 2007). The formal system, which is elitist, discriminatory and installment, cannot alone help man/women to attain all education he/she needs for achievement of self-fulfillment and national development. Terminologies, such as, adult education, continuing education, recurrent education, education permanent, and lifelong education, have been used by different bodies to stress that education is a very useful tool to our life (Torres, 2006).

However, formal education alone is not enough to bring rapid and continuous social and economic development. It is not also the only means of satisfying the education needs of people. People who do not get the opportunity of formal education should be provided with other alternative ways. One of these alternative ways is non-formal education. There are three modes through which one can gain knowledge. Concerning to this, Aggarwal (2002) expressed them as: formal, non formal and informal. In several cases, the non formal education approach is the complement of formal education. The inadequacy of formal education in relation to the needs of some groups of the population becomes a source of justification for non-formal education. In line with this, adult education has a significant role in poverty reduction. It plays very essential function in a rapid changing society by providing information, knowledge, skills, etc. that people need to cope with the changing conditions. Therefore, it is essential to expand the provision of adult education which is less expensive, flexible in terms of time and place in fulfilling the demand of education. 
Ethiopia introduced its Education and Training Policy in 1994 with the aim to address the following five major issues: access, equity, relevance, efficiency and quality. In order to implement the Policy, it also designed the Education Sector Development Program (ESDP) which is now in its fifth phase. It is one of the signatories of the international agreement on Education for All (EFA) which consists of six components. Specifically the fourth goal of Education for All (EFA) calls on countries to "achieve a $50 \%$ improvement in levels of adult literacy by 2015, especially for women and equitable access to basic and continuing education for all"(MoE, 2005).However it is not achieved and restated in ESDP V in 2015.

Furthermore, international initiatives like UNESCO(2000) Ethiopia has implemented a series of poverty eradication plans and it has emphasized the need to overcome the problem of illiteracy if a real socio-economic transformation is to occur. The multifaceted effects of illiteracy could be understood from the following view of Jean-Paul Hautecoeur (1990) cited in Haimanot(2014): In the economy: illiteracy would lead to major losses in production, low productivity, and poor product quality, industrial accidents, etc.; In the social sector: it is associated with the increase in criminality, disease and accidents, with the growing exclusion of new population levels; In private life: illiterate families and individuals display certain psychological disturbances which affect their identity, interfere with their role and lead to isolation and behavior characterized by failure, aggressiveness, etc.

In culture: the cultural capital of the nation is threatened due to the competition of imported values, etc. In the socio-political sector: it is a direct threat to democracy, to national security, and national unity. Functional Adult Literacy (FAL) in Ethiopia is an approach designed to impart reading, writing and numeracy skills among adults side by side with other functional knowledge and skills in agriculture, health and other livelihood activities.

The National Adult Education Strategy implemented through the ESDP IV put a special policy focus on IFAE. The IFAE two-year program for 15-60 year olds, provides mother tongue reading, writing and arithmetic skills development integrated with practical knowledge and skills, for example in relation to family health, hygiene and sanitation. According to Amadu Musah Abudu(2013) in Ghana, The classes are in batches starting from batch 1 to batch 18. A class consist of about 25-30 learners. On the average each class meet at least 6 hours per week.

It is designed to make use of inputs from other development workers (agriculture, health, etc.) and builds on indigenous knowledge. It seeks to link numeracy and literacy skills to livelihoods and skills training in agriculture (including off-farm activities), health, civic and cultural education, etc. and requires delivery by various governmental and on-governmental service providers in multiple setting(MoE, 2015).

Under the federal system of government, education is a shared responsibility of the federal, regional state and Woreda governments (MoE, 2006). The MOE gives technical and policy support to Regional states and manages university education. Regional states and Woredas have the mandate to run formal and non-formal education programs. WEOs (Woreda education offices) are responsible for primary, secondary education as well as non formal education for adults and youth out of school. To alleviate this illiteracy problem the Ethiopian government focused on functional adult literacy program that aims to empower adult member of the society to actively take part in the national development and poverty reduction strategies (MOE, 2006:47).

Integration of literacy and life skills is essential in order to challenge different life problems. Integrated functional adult literacy program enables adult to take informed decision in daily life of an individual or groups'. It also empowers person or people to participate actively in ones or their affairs. It helps beneficiaries to generate income, fight against poverty and promote lifelong learning and so on. Concerning this DVV International (2005) state that:" The essence of functionality and the need are directly related to the relevant and appropriateness of the program to successful challenges of various life problems".

Among the benefits of functional adult literacy revealed by various evaluations is that it increase peoples responsiveness to and even demand for various life improving services. Even though the above mentioned opportunities were given to the adults, still there is a challenge that hampers the literacy of adults and a great gap between theory and practical implementation in many areas of our country. Even though integrated functional adult literacy is important, the commitment of the leaders, the integration of the concerned government officials and the community representatives, the lack of funding, the difference in concept of understanding of IFAE and poor coordination of the integrated sectors hinders its implementation.

In 2008, the country endorsed its National Adult Education Strategy and at the same time Memorandum of Understanding (MOU) was signed by various line ministries. These were the Ministry of Agriculture and Rural Development, Ministry of Health, Ministry of Labor and Social Affair, Ministry of Women“s Affairs and Ministry of Youth and Sports. Similar agreements have been agreed at Oromia region, of the Shashemene City Administration Memorandum of Understanding (MOU) was signed in Shashemene City Administration with different integrated sectors such as, education office, health office, Women's Affairs, Urban Agriculture, small and medium enterprise and Youth and Sports. However, much effort was not to alleviate the existing literacy challenges in the study area.

Shashemene City Administration has eight Sub-Cities. Currently, six hundred thrifty four IFAE learners attending the program in twenty one FAL centers in Sheshamane city. Even though Shashemene city has 
implemented the IFAE program for the last seven years, no scientific study was conducted on the effects, of IFAE program implementation. In light of the above mentioned reason the researchers would like to conduct this study.

\section{Methods}

\subsection{Research design}

According to James and Sally (2001) descriptive survey is a method which was used to explore relationships between variables and allows generalizations across the population. Therefore, it was used in this study because it enables the researcher to obtain accurate information for large numbers of population using a small sample. A survey design was referred because it concerns itself with describing practices to determine the current status of that population with regard to one or more variables. The usefulness of this design was convenient in collecting extensive quantifiable data from a large sample of respondents within a short period of time

\subsection{Research method}

In this study, mixed method (qualitative and quantitative) with parallel convergent design was used to generate and analyze information obtained from diverse groups of respondents. The quantitative method helps the researcher to analyze the quantitative data obtained through the use of a questionnaire with close-ended question items whereas the qualitative method helps to analyze the data obtained through the use of semi-structured interview guide, focus group discussion (FGD) and observation checklist.

\subsection{Data sources}

The data for this study was obtained from both primary and secondary. The primary data for this study was collected from IFAL learners, sub-city chair persons, facilitators, IFAE coordinators, women affairs experts, youth and sport experts, health extension workers, school supervisors, school directors and Shashemene city education office experts using questionnaire, FGD and interview. Whereas, secondary data was obtained from documents. These documents include: minutes, centers, school records on IFAL implementation, policy and strategy documents related to IFAL.

\subsection{Sample and Sampling techniques}

Out of the available 21 IFAE centers of the sub-city, the following ten IFAE centers were included by using simple random sampling technique: Burke Gudina first cycle, Biruh idget fana private school first cycle, Melka Essa first cycle, Arada kebele, Biherawi first cycle, Lucy private school first cycle, Salam private school first cycle, Lucy 04 private school first cycle, Birbirsa kerata first cycle and katolic 01private school first cycle. With regards to sample the population under the study, out of 400 adult learners, 120 were selected by using the formula of Cohen et.al (2013). Therefore, the sample size for adult learners was calculated as follows: 400x30\% So that, $(=120)$. However, health extensions workers, supervisors, school Principals, City education experts, Sub- city chair person, women affairs experts and youth and sport experts were selected in available sampling techniques because these respondents were the only option to be included in the study. So that 120 adult learners, 4 health extensions workers, 10 facilitators, 4 supervisors, 5 school Principals, 2 City education experts, 5 Sub- city chair person, 2 women affairs experts and 2 youth and sport experts, 2 Small and medium enterprise experts were respondents of this study. The sums of these respondents give rise to 156 subjects. Generally, 156 respondents were included in this study. In short target population, sample and the sampling techniques employed in the study were:-

\subsection{Data collection instruments}

In this study, questionnaire; unstructured interview, focus group discussion and observation check list. The questionnaires were prepared in English language then translated to Afan Oromo to minimize the language barrier and used to collect data from groups of respondents IFAE learners and facilitators. According to Best, (2004), questionnaire was widely used in educational research to obtain information about certain conditions and practices, and inquire into opinions and attitudes of individuals or groups. On the other hands, unstructured interview was employed to collect factual and detail information from Shashemane City education office IFAL experts, City education supervisor, health extension workers, Sub City chair person, Women affairs Youth and Sport and SME experts. Since the main purpose of interview was to get additional information from responsible bodies, the key content of the questionnaires were included in the interview questions in order to supplement questionnaires responses. In addition, Focus group discussion (FGD) observations were used to triangulate information obtained by using other data collection instruments and watching to an interaction or phenomenon as it takes place respectively.

\subsection{Methods of data analysis.}

In this study the response that was obtained from questionnaire, interview, focus group discussion and observation were organized, summarized and analyzed qualitatively and quantitatively. To analyze the quantitative data for 
example, the data gathered through close ended questions was first presented in the tables and statistically analyzed. On the other hand, the collected data was coded and analyzed using SPSS-20. Quantitative data were analyzed using percentage, frequency, mean and independent t-test. Qualitative data were analyzed systematically using narrative and quotation approach to substantiate quantitative analysis.

\section{Result}

\subsection{Socio demographic characteristics of the respondents}

The major demographic characteristics of respondents include sex, age, marital status, educational level and their work of experiences.

Table 4.1 Socio demographic characteristics of the respondents

\begin{tabular}{|c|c|c|c|c|c|c|}
\hline \multirow[t]{2}{*}{ R.No. } & \multirow{2}{*}{\multicolumn{2}{|c|}{ Variables }} & \multicolumn{2}{|c|}{ IFAL Learners } & \multicolumn{2}{|c|}{ IFAL Facilitators } \\
\hline & & & No & $\%$ & $\mathrm{No}$ & $\%$ \\
\hline \multirow[t]{2}{*}{1} & \multirow[t]{2}{*}{ Sex } & Male & 24 & 21.8 & 7 & 70 \\
\hline & & Female & 86 & 78.2 & 3 & 30 \\
\hline \multirow[t]{4}{*}{2} & \multirow[t]{4}{*}{ Age } & Below 20 & 42 & 38.2 & 3 & 30 \\
\hline & & $21-30$ & 48 & 43.6 & 6 & 60 \\
\hline & & $31-40$ & 16 & 14.5 & 1 & 10 \\
\hline & & Above 40 & 4 & 3.6 & & \\
\hline \multirow[t]{4}{*}{3} & \multirow[t]{4}{*}{ Marital status } & Single & 48 & 43.6 & 6 & 60 \\
\hline & & Married & 58 & 52.7 & 4 & 40 \\
\hline & & Divorced & 4 & 3.6 & & \\
\hline & & Widow & & & & \\
\hline \multirow[t]{3}{*}{4} & \multirow[t]{3}{*}{ Education level } & Level one & & & & \\
\hline & & Level two & 110 & 100 & & \\
\hline & & $10-12$ & & & 10 & 100 \\
\hline \multirow[t]{3}{*}{5} & \multirow[t]{3}{*}{ Work experience } & $1-5$ & & & 10 & 100 \\
\hline & & $6-10$ & & & & \\
\hline & & $11-20$ & & & & \\
\hline \multicolumn{2}{|c|}{ Total Population } & & 110 & & 10 & \\
\hline
\end{tabular}

Source: Field survey, 2018

As indicated in table 1 above, a total of 120 respondents of IFAE learners and facilitators were included in the study. $31(25.83 \%)$ respondents were males while the remaining $89(74.17 \%)$ are females. The researcher sampled proportion of respondents by sex proportion of their enrollment.

With regards to age of respondents, the IFAE facilitators and learners, $45(37.5 \%)$ were in the age group of below 20 years. The others 54 (45\%) respondents were between the age group of 21-30 years. Thus the majority of the respondents were in this age group. 17 (14.17\%) respondents were between the age group of 31-40 years. and the rest very few $4(3.33 \%)$ respondents were in the age group of above 40 years.

Regarding to marital status of the respondents the majorities $6(60 \%)$ of IFAE facilitators and $48(43.6 \%)$ of IFAE learners were single, while $4(40 \%)$ of IFAE facilitators, $58(52.7 \%)$ of IFAE learners were married. Whereas $4(3.6 \%)$ IFAE learners were divorced.

With regards to educational level of the same table, $10(100 \%)$ were grade 10-12 complete. All IFAE learners $110(100 \%)$ were level two and they were able to read and write. Regarding item 5, the experience of facilitators, most of them had a work experience ranging between one and five years.

Regarding to work experiences of the Sub City chair person, City education supervisors, health extension workers, School Principals, IFAE experts from Women affairs, City education experts, SME experts and IFAE experts from Youth and sport indicate that all the $22(91.67 \%)$ of them are first degree holders and The remaining $2(8.33 \%)$ health extension workers had diploma. The majority of the them are 6 and above years of service experience

4.2. Practice of IFAL program implementation program implementation.

Table 4.2: Respondents response based on the practice of program implementation.

\begin{tabular}{|c|c|c|c|c|c|c|c|c|}
\hline \multirow[t]{3}{*}{ No } & \multirow[t]{3}{*}{ Activities } & \multirow[t]{3}{*}{ Response } & \multicolumn{6}{|c|}{ The extent of IFAE practice } \\
\hline & & & \multicolumn{2}{|c|}{$\begin{array}{l}\text { IFAE } \\
\text { learners }(110)\end{array}$} & \multicolumn{2}{|c|}{ Facilitators(10) } & \multicolumn{2}{|c|}{ Total(120) } \\
\hline & & & Freq. & $\%$ & Freq. & $\%$ & Freq. & $\%$ \\
\hline \multirow[t]{3}{*}{1} & \multirow{3}{*}{$\begin{array}{l}\text { To what extent do IFAE } \\
\text { implemented at your center? }\end{array}$} & Low & 20 & 18.2 & 1 & 10.0 & 21 & 17.5 \\
\hline & & Medium & 85 & 77.3 & 8 & 80.0 & 93 & 77.5 \\
\hline & & High & 5 & 4.5 & 1 & 10.0 & 6 & 5 \\
\hline
\end{tabular}




\begin{tabular}{|c|c|c|c|c|c|c|c|c|}
\hline \multirow[t]{3}{*}{ No } & \multirow[t]{3}{*}{ Activities } & \multirow[t]{3}{*}{ Response } & \multicolumn{6}{|c|}{ The extent of IFAE practice } \\
\hline & & & \multicolumn{2}{|c|}{$\begin{array}{l}\text { IFAE } \\
\text { learners(110) }\end{array}$} & \multicolumn{2}{|c|}{ Facilitators(10) } & \multicolumn{2}{|c|}{ Total(120) } \\
\hline & & & Freq. & $\%$ & Freq. & $\%$ & Freq. & $\%$ \\
\hline \multirow[t]{3}{*}{2} & \multirow{3}{*}{$\begin{array}{l}\text { To what extent IFAE improves the } \\
\text { learners living condition of health } \\
\text { care and communication with their } \\
\text { facilitators? }\end{array}$} & Low & 5 & 4.5 & 1 & 10.0 & 6 & 5 \\
\hline & & Medium & 15 & 13.6 & - & - & 15 & 12.5 \\
\hline & & High & 90 & 81.8 & 9 & 90.0 & 99 & 82.5 \\
\hline \multirow[t]{3}{*}{3} & \multirow{3}{*}{$\begin{array}{l}\text { Levels of IFAE program to promote } \\
\text { parents to encourage and send their } \\
\text { children to school. }\end{array}$} & Low & 10 & 9.1 & - & - & 10 & 8.33 \\
\hline & & Medium & 20 & 18.2 & 2 & 20.0 & 22 & 18.33 \\
\hline & & High & 80 & 72.7 & 8 & 80.0 & 88 & 73.33 \\
\hline \multirow[t]{3}{*}{4} & \multirow{3}{*}{$\begin{array}{l}\text { To what extent IFAE program } \\
\text { improve the learners understanding } \\
\text { about their rights and responsibilities } \\
\text { within the society. }\end{array}$} & Low & 10 & 9.1 & 1 & 10.0 & 11 & 9.17 \\
\hline & & Medium & 30 & 27.3 & 2 & 20.0 & 32 & 26.67 \\
\hline & & High & 70 & 63.6 & 7 & 70.0 & 77 & 64.17 \\
\hline
\end{tabular}

Source: Field survey, 2018

As indicated in Table 2 above, the respondents were asked about the extent to IFAE implemented at your center, most $85(77.3 \%)$ of the IFAE learners and $8(80 \%)$ of the IFAE facilitators i.e $93(77.5 \%)$ said Medium and the rests $6(5 \%)$ and $21(17.5 \%)$ of the total respondents accounted low and high respectively.

On the same table respondents asked about the extent IFAE improves the learners living condition of health care and communication with their facilitators. Accordingly, the majority $99(82.5 \%)$ of the total respondents replied high and the rests $15(12.5 \%)$ and $6(5 \%)$ of the total respondents rated medium and low respectively.

Regarding item no 3 of table (2), the respondents asked about levels of IFAE program to promote parents to encourage and send their children to school $88(73.33 \%)$ of the total respondents rated high, $22(18.33 \%)$ of respondents rated medium and $10(8.33 \%)$ of respondents rated low.

Finally the respondents asked about the extent IFAE program improve the learners understanding about their rights and responsibilities within the society, the majority 77(64.17\%) of the total respondents replied high and the rests $32(26.67 \%)$ and $11(9.17 \%)$ of the total respondents rated medium and low respectively.

Table 4.3: Response based on the current practice of IFAL program implementation.

\begin{tabular}{|c|c|c|c|c|c|c|c|c|}
\hline \multirow{3}{*}{ No } & \multirow{3}{*}{ Activities } & \multirow{3}{*}{ Response } & \multicolumn{6}{|c|}{ The extent of IFAE practice } \\
\hline & & & \multicolumn{2}{|c|}{$\begin{array}{l}\text { IFAE } \\
\text { learners }(110) \\
\end{array}$} & \multicolumn{2}{|c|}{ Facilitators(10) } & \multicolumn{2}{|c|}{ Total(120) } \\
\hline & & & Freq. & $\%$ & Freq. & $\%$ & Freq. & $\%$ \\
\hline \multirow[t]{3}{*}{1} & \multirow{3}{*}{$\begin{array}{l}\text { To what extent do you think the time } \\
\text { (the day, hour and the month) has } \\
\text { convenience to attend education? }\end{array}$} & Low & 15 & 13.6 & 1 & 10.0 & 16 & 13.33 \\
\hline & & Medium & 15 & 13.6 & 1 & 10.0 & 16 & 13.33 \\
\hline & & High & 80 & 72.7 & 8 & 80.0 & 88 & 73.33 \\
\hline \multirow[t]{3}{*}{2} & \multirow{3}{*}{$\begin{array}{l}\text { To what extent the place of } \\
\text { educational provision (IFAE center) } \\
\text { has convenience to attend the lesson? }\end{array}$} & Low & 10 & 9.1 & 2 & 20.0 & 12 & 10 \\
\hline & & Medium & 75 & 68.2 & 6 & 60.0 & 81 & 67.5 \\
\hline & & High & 25 & 22.7 & 2 & 20.0 & 27 & 22.5 \\
\hline \multirow[t]{3}{*}{3} & \multirow{3}{*}{$\begin{array}{l}\text { To what extent do you think IFAE } \\
\text { facilitators are skilled and cooperative } \\
\text { in teaching adult learners? }\end{array}$} & Low & 23 & 20.9 & - & - & 23 & 20.9 \\
\hline & & Medium & 87 & 79.1 & - & - & 87 & 79.1 \\
\hline & & High & - & - & - & - & - & - \\
\hline \multirow[t]{3}{*}{4} & \multirow{3}{*}{$\begin{array}{l}\text { Level of evaluation and monitoring } \\
\text { system of coordinated sectors? }\end{array}$} & Low & 22 & 20.0 & 2 & 20.0 & 24 & 20 \\
\hline & & Medium & 88 & 80.0 & 7 & 70.0 & 95 & 79.17 \\
\hline & & High & - & - & 1 & 10.0 & 1 & 10 \\
\hline \multirow[t]{3}{*}{5} & \multirow{3}{*}{$\begin{array}{l}\text { Level of budget allocated to } \\
\text { implement IFAE Program at your } \\
\text { center? }\end{array}$} & Low & 95 & 86.4 & 8 & 80.0 & 103 & 85.83 \\
\hline & & Medium & 15 & 13.6 & 2 & 20.0 & 27 & 22.5 \\
\hline & & High & 5 & - & - & - & - & - \\
\hline \multirow[t]{3}{*}{6} & \multirow{3}{*}{$\begin{array}{l}\text { To what extent the IFAE facilitators } \\
\text { get adequate training? }\end{array}$} & Low & 77 & 70.0 & 7 & 70.0 & 84 & 70 \\
\hline & & Medium & 33 & 30.0 & 3 & 30.0 & 36 & 30 \\
\hline & & High & - & - & - & - & - & - \\
\hline \multirow[t]{3}{*}{7} & \multirow{3}{*}{$\begin{array}{l}\text { To what extent the IFAE program } \\
\text { improves the skill of reading, writing } \\
\text { and counting among parents and their } \\
\text { children? }\end{array}$} & Low & 11 & 10.0 & 1 & 10.0 & 12 & 10 \\
\hline & & Medium & 23 & 20.9 & 3 & 30.0 & 26 & 21.67 \\
\hline & & High & 76 & 69.1 & 6 & 60.0 & 82 & 68.33 \\
\hline
\end{tabular}

Source: Field Survey 2018

Regarding item no. 1 of table (3), the respondents asked about the extent do you think the time (the day, hour and the month) has convenience to attend education. The majority of the total respondents $88(73.33 \%)$ of 
participants indicated that the time to attend education is convenient. This is because the participants choose the appropriate time for education. Regarding item no. 2 of table (3) 81(67.5\%) of the total respondents respond that the convenience of IFAE centers were medium. But $12(10 \%)$ the respondents revealed that the literacy centers were inconvenient to learn.

Regarding item no. 3, the IFAE learners were asked about the extent to the facilitators are skilled and cooperative in teaching adult learners. Accordingly the majorities 87(79.1\%) said medium and 23(20.9\%) said low.

Regarding level of evaluation and monitoring system of coordinated sectors of Item 4 above, the majority $95(79.17 \%)$ of the total respondents rated medium. The rests $1(10 \%)$ and $24(20 \%)$ rated Low and high respectively.

On the same table, IFAE Learners and facilitators were asked whether there is adequate budget for the implementation of IFAE program at the center. Accordingly, the majority $103(85.83 \%)$ of them said that there wasn't adequate budget for the effective implementation of the program. Regarding item no.6 of table (3),IFAE Learners and facilitators were asked about the extent to the IFAE facilitators get adequate training, $36(30 \%)$ of the total respondents rated facilitator had training whereas $84(70 \%)$ of the respondents rated facilitators were untrained.

Regarding item no.7 of table (3), Majority, 82(68.33\%) of the total respondents rated high. the rests of the respondents $26(21.67 \%)$ and $12(10 \%)$ rated medium and low respectively.

\section{Discussion}

The findings showed that the female participation in IFAE program is by far more than that of the males. This implies that the participation of women's in the program is at better condition (level). This confirms that the case in focusing ESDP V adult and non-formal education program resources on increasing female participation and completion rates seem to be improved at Shashemene City Administration. Of the target 19.4 million illiterate adults targeted by the program, 12.4 million (64\%) are female (MoE, 2015).

The result revealed that most of adult learners were found under productive age range between 15 and 60 . The qualifications of all facilitators fit with the IFAE guideline which says they should at least be grade 10 complete. Regarding to Marital status of respondents, the result showed that, respondents have been working and have family responsibility. The result also revealed that, majorities of learners were level two and they were able to read and write. In addition, there was a shortage of more experienced IFAE program facilitators. City is equipped with sufficiently qualified and experienced human resource and these qualification and experience were good to manage the work. In relation to this, to implement IFAE at a large scale, well trained, experienced and qualified personnel are needed to plan, implement, coordinate, supervise, facilitate, monitor and evaluate the program (sandhaas, 2008).

All respondents have experience and responsibilities that were directly related with the IFAE program practiced at the City administration level and they were selected in available sampling techniques because these respondents were the only option to be included in the study.

In order to make the level of IFAE implementation high each sub-city need to develop IFAE program stakeholder, integrations, and participation and build their capacity and also they need to provide adequate budget and material support to the program. In addition to these they need to give necessary training about the implementation of guideline, strategies and IFAL program curriculum framework to facilitator so as to meet the target goal otherwise the program highly affected"

To support this idea, focus group discussion participants confirmed that, IFAE Facilitators taught them a lot. They taught them how to use the toilet, wash hands before and after meals, and how to protect their personal hygiene.

In relation to this, Okech (2009) underpinned that Integrated functional adult education contributes to economic empowerment particularly by enabling IFAE learners to make their goods more effectively and that enable them to plan and participates in income generation and proper decision making. In addition to this, sickness and mortality rates of children and mothers reduced and then increased their life expectancy, improved societal participation on environmental protection practice (natural resource conservation) and improved personal and community hygiene.

The result further affirmed that, IFAE program promotes parents to encourage and send their children to school. Besides most interviewees confirmed the idea that, after the IFAE, program, the attitude they have towards education is totally changed. With regards to teaching learning, it is also confirmed that, IFAE program improved learners understanding about their rights and responsibilities within the society. Participants also indicated that the time to attend education is convenient. This is because the participants choose the appropriate time for education. Most respondents revealed that the literacy centers were inconvenient to learn. City IFAE coordinator interviewees argued that the program at City level has been learnt in primary school. So that anyone who is interested can take part in the training. But it doesn't mean that learning environment is free of problem".

During the observation session, it has been seen that, because of seat, the teaching learning processes carried out in the school system was not in good condition. Because of lack of training (skills on helping adults), IFAE 
facilitators' competency and cooperative in teaching and treating adults were found to be low.

Monitoring and evaluation of coordinated sector on IFAL program was found to be medium. Besides, Shashemene city education supervisors make the necessary follow-ups, visit IFAE centers and discuss periodically with the facilitators as well as IFAE learners. However, a comprehensive and systematic monitoring and evaluation of the program has not yet conducted in the City because of problem of coordination. In relation to this, MoE, $(2005: 44)$ stressed that, monitoring and evaluation system are not the issue of one body but it is the responsibility of different bodies, who participate directly or indirectly in the management system.

The result also revealed that, there wasn't adequate budget for the effective implementation of the program. IFAE coordinators interviewee also confirmed that, no budget allocated for the program. Interviewees also added that, to train IFAE facilitators to run up the program were not easy job. Moreover, giving continuous refreshment training to enhance their capacity was impossible. Even it was difficult to give induction or orientation which lasts 5 days without finance". According to ESDP III, "facilitators will be continuously trained through continuous supervision and support system will be in place (MOE, 2005: 44)

From the result it is also confirmed that, after attending this program the IFAE learner has an ability to read, write and numerate the numbers. Focus group discussion participant also replied that they are confidence and grew their reading and writing capacity through attending IFAE program. They can also read office numbers when they visit health center and government offices."

\subsection{CONCLUSIONS}

Based on the major findings, the following conclusions were drawn. The major objective of the study was to explore the practice, challenges and opportunities of IFAE in Shashemene City Administration. The practice of integrated functional adult education has been benefited considerable number of adults live in the Shashemene City Administration. Their understanding about their rights and responsibilities within the society and the learners living condition of health care and communication with their facilitators improved, promote parents to encourage and send their children to school, improves the skill of reading, writing and counting among parents and their children, improve the learners to living together in peace and harmony, learners accountability to community, participates in income generation and proper decision making, learners capacity to resolve the conflict peacefully, participation in community affairs, the motivation of people to develop self confidence, positive attitudes towards the program, and habit of saving.

However, lack of trained facilitators and expertise, lack of financial support, lack of continuous supervision, low quality of teaching materials, lack of structures system, lack of interest and motivation of facilitators, low political commitments among political leaders to sustain the IFAE program, lack of integrated effort of education office with other Sectors, lack of Permanent budget, inadequate facility and learning environment, lack of coordination among stakeholders(WEO,REB,MOE), lack of connecting the program with primary education program in curricula and low payment of facilitators and coordinators, low awareness of community and poor infrastructure and logistics affect the practice of IFAE program implementation.

\subsection{RECOMMENDATIONS}

Based on the preceding findings and conclusions the following recommendations were forwarded:

Integrated functional adult education plays a pivotal role in attaining sustainable social, economic and political development. However, stakeholders have not played their role on the current practice of IFAE program implementation. Therefore, Oromia regional State and Shashemene City Administration recommended that the participation level of the leading stakeholder sectors is needed to be reviewed and some managerial measure must be considered to ensure equal participation in the City IFAE implementation practices.

Considerable number of facilitators and experts were not well trained on adult education theoretical and practical matters that help us to appropriately manage deliver and assess IFAE program. Hence, it is recommended that regional governments shall develop appropriate and demand driven instructional materials and mode of delivery, afford infrastructures, improve training and employment condition and professionalization of adult educators, design measurement, monitoring and evaluation mechanism at all stages; input, process and outcome to ensure quality IFAE in the region.

Shashemene City Administration education office is advised to organize short-term training for facilitators of integrated functional adult education so that they would improve their facilitation, knowledge and skills. IFAE supervisors shall be advised to provide timely feedback for facilitators concerning the strengths and weaknesses they observed in the practice of IFAE in the centers.

City education officers, sub city adult coordinators, Community, private sectors and NGOs shall assist by supplying the adequate teaching-learning materials such as textbooks, exercise books and others supplementary materials.

Finally, to identify the gap area of the program and to inform implementers and concerned stakeholders; there should be research and consultancy activities with concerned academic institutions in order to made evidence 
based decision.

\section{Acknowledgment}

The authors are grateful for the valuable guidance from two anonymous reviewers. The author is also thankful to Shashemene sub-city all IFAL practitioners' who have supported and/or inspired this work through the various support. Finally, this research did not receive any specific grant from funding agencies in the public, commercial, or not-for-profit sectors.

\section{Conflict of interest}

The author(s) declared no potential conflicts of interest with respect to the research, authorship, and/or publication of this article. And we need to ensure that we are responsible for any conflict of interest that may arise. Also we have not received any fee for patents for the manuscript. Concerning non-financial computing interest the authors encourage the manuscript has significant value for intellectual and/or academic purposes.

\section{Outer's contribution}

Birhanu Jima: Corresponding authors from Department of Adult Education and Community Development, college of Education and Behavioral Studies. He worked a lot from data collection up to analysis, conclusion and recommendation

Ayele Kumsa: Department of Adult Education and Community Development, college of Education and Behavioral Studies. He worked for four years as a lecturer and AECD department Head. He published four journals. $\mathrm{He}$ worked a lot so as to prepare and manuscript. Mr. Ayele contributed on editing the final research before submitting the manuscript for publication.

Belachew Desalegn is an assistant professor in department of agriculture. He contributed a lot for this manuscript. He guide the way to re arranged manuscript. He edited the manuscript before submission.

Furthermore, he played a great role in finding recent reputable journal publishers

\section{References}

Aggrawal. (2002). Recent development and trandes in Education. New Delhi Shipra Puplication.

Amadu Musah Abudu(2013) Complementary Role of Functional Literacy Programs in Accelerating Literacy Rate in Ghana: International Journal of Education and Research Vol. 1 No. 11 November

Best. (2004). Research in Education.New Jersey Orentice Hall.

Cohen Louis, M. L. (2013). Research Methodology in Education.Sixth edition. New York.

Dvv, I. (2005). Institute of international coopretion of the German adult education association ,poverty reduction capacity building through livelyhood skill training at CSTCS and VTCS.The EXPRO in Ethiopia.

English. (2005). International Encyclopedia of adult education . New York: Pal Grave Macmillan.

Getnet, T. (2016). assessment adult leraners perception on social and economic benefit of IFALP. Addis Ababa.

Haima not, Y. (2014). Practice and Challenges of Integrated Functional Adult Education In

James and Sally (2001) 'Returns to women's education'. In King, E.H. and Hill, M.A. (Eds), Women's education in developing countries: Barriers, benefits and policies. Baltimore and London: published for the World Bank by the John Hopkins University Press.

Kala and Chaubey, (2015). Atitude of facalty members to wards fucaity development program and their percieved out comes:Pasfic Business Review international 8(2), 21-30.

Kothari. (2004). Research Methodology ,method and techniques.(2nd ed.New delhi Age instructiona(p) Ltd.

Merriam and Cunningham, 2007). Education for all National review report. Ethiopia.Report perpared for the world Education Forum. Incheon Republic of Korea.

MOE. (July,2006). Academy for Education Department,Action Research in primary Shool In Ethiopia. Addis Ababa: USAID.

MoE. (2006). Decenteralized management of education in Ethiopia:A reference manual. Addis ababa.

MoE. (2015). Education Sector Development Program 2008-2012 E.c. Addis Ababa.

MoE. (2005). Education Sector Development Program III. Addis Ababa.

Okeche, A. (2009). Functional Adult Literacy and poverty reduction.In Sandhaas B.(Ed.) Cross National Encounters in adult education(PP.15-22). Addis Ababa(Ethiopia): DVV International.

Ranjikumar. (1999). Research Methodology A step by step guide for beginners. India.PLt.New Delhi.: SAGE Publication. research), I. o. (1999). Teacher education handbook.addis Ababa by institutional consultancy.

Sandhaas. (2008). "Training of FAL personnel" in focus on adult and non formal education in Ethiopia. NEWSLETTER, No. 22/23 15-25.

Torress. (2003). Life long learning:A new momentum and new apportunity for adult basic learning and education (ABLE)in the South stockhom . Swedish international development corporation Agency.

UNSECO. (2000). Focus on Adult and Non-Formal Education in Ethiopia.New Letter No.6-9. Addis Ababa. 